\title{
Oil Shale of Rif region: natural adsorbents for environmental cleaning
}

\author{
Larbi El Hammari ${ }^{1}$, Souhayla Latifi ${ }^{1.2}$, Asmae Gouza ${ }^{1}$, Omar Boukra ${ }^{1}$, Sanaa Saoiabi ${ }^{1 *}$, and Ahmed Saoiabi ${ }^{1}$ \\ 1 Laboratory of Chimie Appliquée des Matériaux, Department of Chemistry, Faculty of Sciences, Mohammed V University in Rabat, \\ Morocco. \\ 2 Laboratory REMTEX, ESITH (Higher school of textile and clothing industries), Casablanca, Morocco \\ *Corresponding author: sanaa.saoiabi@yahoo.com
}

\begin{abstract}
Oils shales are the largest energy resource in the world and are widely used in the development of industrial fuel and petroleum activities. Oil shale is one of the important mineral resources in Morocco and it has a large reserve, the most important of which is of Timahdit, Tarfaya, and Tangier. Nowadays, the increasing concentration of toxic organic species (Antibiotics, Colorants) in soils and domestic, agricultural, and industrial wastewater has become a major environmental concern. for this reason, we have focused on the interactions of raw oil shale deposits with toxic organic species as part of an additional valuation of national energy resources. Our work is focused on the contribution of organic matter on antibiotic retention, as well as the role of hydrophobic interactions on the molecules-mineral surfaces. The results of the characterizations show the possible contribution of raw oil shales in the accumulation of organic pollutants in soil and water. Thermally treated oil shell powders can be good mineral sorbents for environmental cleaning.
\end{abstract}

\section{Introduction}

Rapid industrialization and urbanization have resulted in the deterioration of the quality of water, air, and soil. Generally, industrial, agricultural, or urban human activities produce polluting substances of different kinds: physical, organic and microbiological, or chemical. Most of them impact water quality. This pollution can be permanent (domestic discharges), periodic or accidental [1]. Natural waters are contaminated with heavy metals, dyes, and pharmaceuticals from mining, industrial waste, and discharges [2]. Discharges from pharmaceutical industries are considered as pollutants that influence the ecological system and cause human and animal health problems [3].

Furthermore, water decontamination has become a very important subject for researchers, for this several purification methods have been used, for example, Solvent extraction [4], ion exchange resin[5], membrane technique [6], Adsorption [7] .

Adsorption consists of using adsorbents of organic or inorganic origin such as oxides [8] of activated carbon [9], clays[10], phosphates[11], zeolites[12] and silicates [13]. But their high costs have limited their large-scale use for adsorption of pharmaceuticals. For this, researches have been directed towards the use of natural adsorbents in order to minimize the cost and enhance the value of natural resources.

In addition, Morocco is among the countries which have significant resources of oil shale, it is ranked 6th in the world with a potential of 53 billion barrels of oil including more than 37 billion barrels planned in the two main deposits of Bab Taza, Arba Ayacha and Tangier [14]. As part of an additional valorization of these national energy resources, we are interested in the development of materials based on oil shale capable of retaining polluting compounds present in certain industrial effluents.

In this context, E. Khouya et al prepared a new adsorbent from Moroccan oil shales in the R3 layer of the Tarfaya region to eliminate methylene blue (BM) [15], H. Ouasif et al carried out a comparison between the clays of the Ouled Saïd zone and the oil shales of the "M" layer of the Timahdit zone and for the adsorption of methyl blue [16] and Y. Miyah et al have demonstrated the powerful capacity of Oil shale from the Timahdit region to remove cationic dyes from methylene blue [17].

The objective of this research is to compare the structural and mineralogical characteristics of oil shales in the Rif region. We have focused on the interactions of raw oil shale deposits with toxic organic species such as antibiotics whose increasing concentration in soils and domestic, agricultural, and industrial wastewater has become a major environmental concern. The analysis shed light on the contribution of organic matter on antibiotic retention as well as the key role of hydrophobic interactions on molecule-mineral surface interactions. 


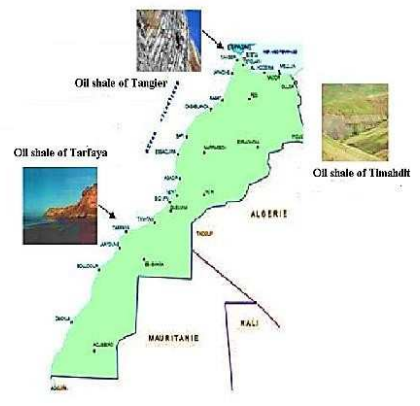

Fig.1: Map present different regions containing oil shale in Morocco

\section{Experimental}

\subsection{Preparation of samples (Adsorbents)}

The oil shale used in this study was obtained from Tetouan (SBTE), Arba Ayacha (SBAA), Bab Taza (SBBT), and Tanger (SBTA) deposits in the RifMorocco region. Before use, this material requires treatments such as crushing and washing. The fraction of $100-400 \mu \mathrm{m}$ grain size was washed with distilled water several times to remove the soluble matter. Elemental analysis, of the main constituents of oil shale, is carried out using a spectrofluorimeter X. The results of this chemical analysis are summarized in Table 1.

Table 1: Chemical compositions of oil shale in the Rif region.

\begin{tabular}{ccccc}
\hline$(\%)$ & SBTE & SBBT & SBAA & SBTA \\
\hline $\mathrm{SiO}_{2}$ & 70.04 & 73.78 & 84.46 & 80.22 \\
$\mathrm{Al}_{2} \mathrm{O} 3$ & 12.34 & 11.87 & 3.908 & 7.93 \\
$\mathrm{Fe} 2 \mathrm{O} 3$ & 3.569 & 1.808 & 0.644 & 2.17 \\
$\mathrm{CaO}$ & 0.36 & 0.191 & 0.013 & 0.84 \\
$\mathrm{MgO}$ & 1.31 & 1.323 & 0.48 & 1.22 \\
\hline
\end{tabular}

\subsection{Selected antibiotics (Pollutants)}

We selected two antibiotics from the fluoroquinolone family (ciprofloxacin and ofloxacin) and one antibiotic from the tetracycline family (oxytetracycline). These antibiotics are consumed in very large quantities in human medicine. A proportion of up to $80 \%$ of the active ingredient can be excreted and unchanged for these molecules. These antibiotic residues are then released into the wastewater without any prior treatment.

\subsection{Characterization}

The powders SBTE, SBAA, and SBBT were characterized by X-ray diffraction using a siemens D5000 model X-ray diffractometer operating with a copper anticathode $(\lambda \mathrm{cu}=1.54 \AA$ ) at $20 \mathrm{kV}$ and $5 \mathrm{~mA}$ and for an angular range $2 \theta$ from $10^{\circ}$ to 60 . The study of the functional groups present in the shales was carried out by Fourier transmission infrared spectroscopy in transmittance mode in the spectral range which extends from $4000 \mathrm{~cm}^{-1}$ to $500 \mathrm{~cm}^{-1}$ with a resolution of $2 \mathrm{~cm}^{-1}$, and the thermal degradation of different samples was carried out by thermogravimetric analyzes (TGA) using a Versatherme HM machine over a temperature range of $25^{\circ} \mathrm{C}$ up to $800{ }^{\circ} \mathrm{C}$, with a heating rate of $10^{\circ} \mathrm{C} / \mathrm{min}$ under area.

\subsection{Protocol of adsorption study}

The study of the adsorption of the three antibiotics on the oil shale was carried out under static conditions by using a magnetic stirrer of 15 stations allowing the use of a series of experiments aimed at working under the same conditions of speed and temperature. The system makes it possible to have better contact between adsorbate-adsorbent, avoiding any decantation of the adsorbent. The temperature is kept constant throughout the experiment, because of its effect on the adsorption phenomenon.

Stock solutions of the studied pollutants of concentration $100 \mathrm{mg} / \mathrm{L}$ were prepared. Each of the stock solutions was suitably diluted with distilled water to obtain daughter solutions at desired concentrations. An adsorbent mass was added to the contaminated solution. To determine the time required to reach the adsorption balance of the pollutant, experiments were carried out on a volume of $100 \mathrm{~mL}$ of an adsorbate solution of concentrations from 10 to $100 \mathrm{mg} / \mathrm{L}$, at initial $\mathrm{pH}$ and with a dose of adsorbent/adsorbate volume of $2 \mathrm{~g} / \mathrm{L}$. At regular intervals, samples are taken. After solid-liquid separation by filtration, they are analyzed by UV / Vis spectrophotometer at corresponding wavelengths.

\section{Results and discussion}

\subsection{X-ray diffraction}

$\mathrm{X}$-ray diffraction analysis was done to determine the crystal structure of the prepared shale (fig.2)

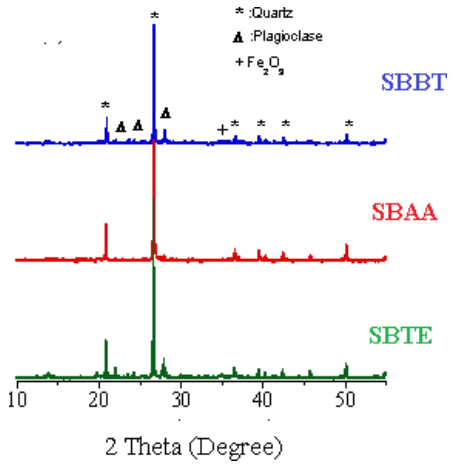

Fig.2: X-ray diffraction diagrams of oil shale in the Rif region steamed at $100^{\circ} \mathrm{C}$.

The structural study of the Tetouan, Bab-Taza, and Arba Ayacha oil shale (fig 2) shows that these are wellcrystallized materials characterized by a principal phase characteristic of quartz-SiO2 accompanied by other phases relating to metal oxides, the main one attributable to plagioclase $\left(\mathrm{CaAl}_{2} \mathrm{Si2} 28\right)$ [18].

Generally, clay forms most often layers in most 
deposits in the form of hydro-oxysilicates whose composition is very variable. It may also contain some iron oxide and magnesia. It should be noted that the shales studied have undergone preliminary washing treatments to eliminate or reduce the amount of clay that can be inserted in the layers or layers of shale rock. The effectiveness of this pre-treatment was authenticated by $\mathrm{XRD}$, reflecting the absence of clay-derived phases such as kaolinite and dolomite [19]. Consequently, the structural characterization of oil shale in this region shows, in addition to quartz, low-intensity crystalline phases relative to metal oxides, or which are sometimes not detectable at XRD but are quantified by chemical analyses.

\subsection{IR- Analysis}

FTIR study was carried out to determine the functional bands present in the studied shales (fig.3).

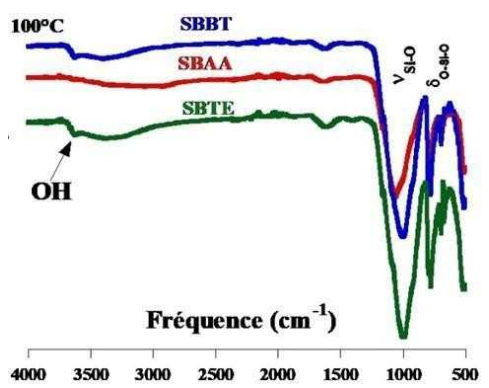

Fig.3: Infrared absorption spectra of oil shale in Rif region steamed at $100^{\circ} \mathrm{C}$

The infrared absorption spectra of the oil shale of the Rif region (Tetouan, Bab Taza, and Arba Ayacha) are presented in Figure 3 which shows several absorption bands indicating the presence of $\mathrm{SiO}_{2}$ groups.

The analysis by FTIR spectroscopy reveals several bands, in particular those attributable to $\mathrm{SiO}_{2}$ groups. The samples at $100^{\circ} \mathrm{C}$ show a low-intensity band observed around $3630 \mathrm{~cm}^{-1}$ relative to the hydroxyl groups $\left(\mathrm{OH}^{-}\right)$attributable to the hydroxylation of the metal oxides and the probable presence of the hydroxylated forms of $\mathrm{SiO}_{2}$ [20], especially in the case of oil shale in Tetouan and Bab-Taza. The absorption bands around $3400 \mathrm{~cm}^{-1}$ and $1600 \mathrm{~cm}^{-}$ ${ }^{1}$ characterize the hydration of shales by the presence of water on the surface of the structure, which disappears with their heat treatment of these oil shales [19].

\subsection{Thermogravimetric Analysis}

To follow the thermal degradation of shales in the Rif region (SBTE, SBBT, SBAA), thermogravimetric analysis was carried out. Figure 4 shows the mass loss of shales in the function of temperature.

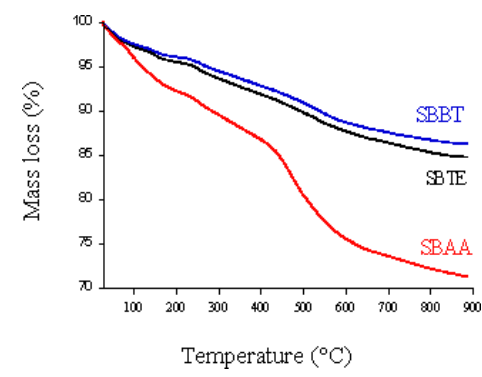

Fig.4 Thermal degradation of SBBT, SBTE, and SBA Samples

Figure 4, represents the thermal behaviors of the three oil shales of the Rif region (Tetouan, Bab Taza, and Arba Ayacha) as a function of temperature. The thermograms obtained indicate the same major mass losses except the thermal behavior of the Arba Ayacha oil shale, the thermogram of which looks different from that of other oil shales (Tetouan and Bab Taza). Indeed, the first loss between $25^{\circ} \mathrm{C}$ and $200^{\circ} \mathrm{C}$ is attributed to the dehydration of powders for all thermograms [21]. On the other hand, the second loss differs according to the nature of the shale, it is observed between $200^{\circ} \mathrm{C}$ and $560^{\circ} \mathrm{C}$ for the oil shale of Bab-Taza and Tetouan, while that characteristic of the shale of the Arba Ayacha is located between $200^{\circ} \mathrm{C}$ and $460^{\circ} \mathrm{C}$, which corresponds to the degradation of the organic matter, accompanied by a dehydroxylation of the metal hydroxyls [22].

The last loss can be attributed to the structural transformation of some minerals as confirmed by XRD [23]. In this last step, the weight loss relative to the different schists studied follows the following order: SBAA $(12 \%)>\operatorname{SBTE}(3 \%)=\operatorname{SBBT}(3 \%)$.

Note also that in the case of Arba Ayacha Shale, we can divide the last loss into two areas, between 460-650

${ }^{\circ} \mathrm{C}$ and $650-900{ }^{\circ} \mathrm{C}$; this may be related to the nature of the mineral species and the combustible resistivity of the organic molecules present in these geomaterials [23].

\subsection{Adsorption studies}

In order to make a comparative study of the adsorption capacity of oil shale from deposits in the Rif region (Arba Ayacha, Bab Taza, and Tetouan), a series of adsorption experiments of CIP, OFL, and OTC antibiotics on these Steamed geomaterials was carried out.

Sorption isotherm studies (fig 5) were conducted in the range of $0-150 \mathrm{mg} \mathrm{L}-1$ antibiotic concentration at the same $\mathrm{pH}$. At selected time intervals, the suspensions were sampled by centrifugation and the antibiotic concentration in the supernatant was monitored using a UV-visible spectrophotometer (Perking Elmer Lamda II) at $354 \mathrm{~nm}, 273 \mathrm{~nm}$, and $295 \mathrm{~nm}$ for OTC, CIP and OFL, respectively. For low levels of antibiotics, all UV visible analyses were controlled by high performance liquid chromatography (HPLC). The amount of sorbed antibiotic was calculated by using: 
Where:

$$
q t=\frac{C 0-C e}{m} V
$$

qt $\left(\mathrm{mg} \cdot \mathrm{g}^{-1}\right)$ is the amount of adsorbed antibiotic at time t;

$\mathbf{C}_{\mathbf{0}}$ and $\mathbf{C}_{\mathbf{t}}$ are the antibiotic concentration in solution $\left(\mathrm{mg} \mathrm{L}^{-1}\right)$ at $\mathrm{t}=0$ and $\mathrm{t}$;

$\mathbf{V}$ is the volume (L) of the antibiotic solution;

$\mathbf{m}$ is the weight $(\mathrm{g})$ of the sorbent.
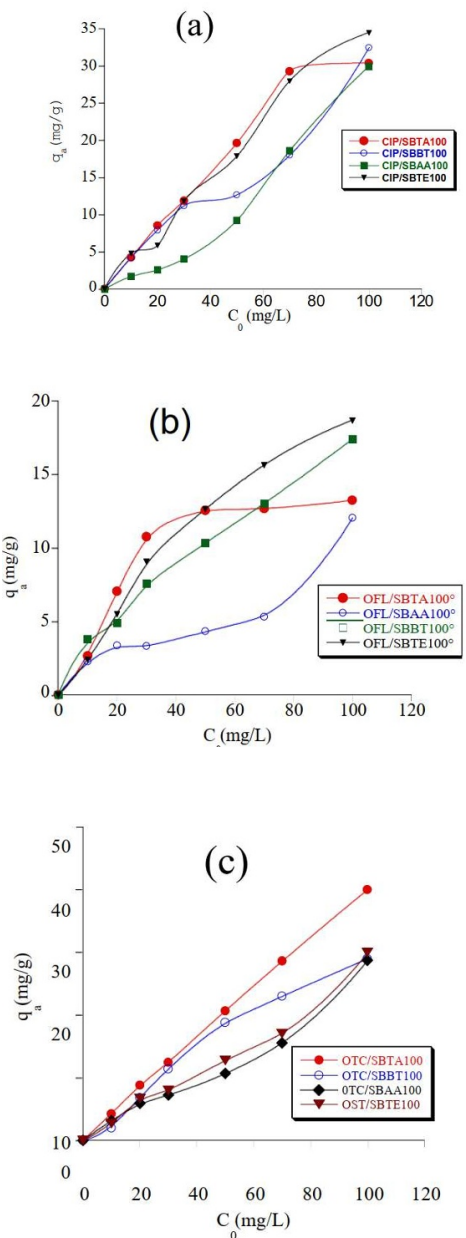

Figure 5: Adsorption isotherms of antibiotics on (a) CIP/SBTA, CIP/SBBT, CIP/SBAA and CIP/SBTE, (b) OFL/SBTA, OFL/SBBT, OFL/SBAA and OFL/SBTE, (c) OTC/SBTA, OTC/SBBT, OTC/SBAA and OTC/SBTE

Table 2: Percentage of antibiotic adsorption (OTC, CIP, and $\mathrm{OFL})$ by the steamed oil shale of the Rif $(\mathrm{C} 0=50 \mathrm{ppm})$

\begin{tabular}{cccc}
\hline & \multicolumn{3}{c}{ Percentage of elimination (\%) } \\
\cline { 2 - 4 } Oil shale & CIP & OFL & OTC \\
& & & \\
\hline SBTA & 78.5 & 50 & 84 \\
\hline SBAA & 37.0 & 17.3 & 42.8 \\
\hline SBBT & 50 & 41.2 & 75.2 \\
\hline SBTE & 71.2 & 50 & 51 \\
\hline
\end{tabular}

From table 2, we conclude that the Moroccan shale studied has a very high adsorption capacity towards the three drugs. The adsorptive capacity of ciprofloxacin on Tetouan shales is large $(71.2 \%)$, whereas it decreases in the case of adsorption of oxytetracycline on the same support (51\%). We also note that oxytetracycline (OTC) adsorption capacity on Bab Taza bituminous shales $(75.2 \%)$ is important, while that of ciprofloxacin is lower (50\%). Similarly, the adsorption capacity of the ArbaAyacha oil shale is the lowest compared to that of the other schists in the Rif region, it does not exceed $37 \%$ for the CIP and $43 \%$ for the OTC. On the other hand, the adsorption of ofloxacin (OFL) on all the shales studied does not seem satisfactory; its elimination on the shale of Bab Taza is only $41.2 \%$ and does not exceed $50 \%$ on the shale of Tetouan. This difference in adsorption capacity by these different shales can be explained by the percentage of silicate present in each sample.

The use of these geomaterials from the Rif region for the treatment of wastewater seems to be an interesting solution for the future, using them as inhibitors of infiltration of pharmaceutical substances towards the water tables.

\section{Conclusion}

Oil shale refers to mineral deposits widely applied in fuel and oil industrial processes and is considered one of the largest energy resources in the world. The chemical composition of these rocks varies from one deposit to another including inorganic and organic matters.

Here, we focused on the interactions of raw oil shale deposits with organic toxic species as antibiotics and dyes whose increasing concentration in soils and domestic, agricultural, and industrial wastewaters has become a major environmental concern.

Analyses enlighten the contribution of the organic matter on antibiotic retention as well as the key role of hydrophobic interactions on the molecule-mineral surface interactions. Our results emphasize the possible contribution of raw oil shale in the accumulation of organic pollutants in soils and water and suggest that thermally treated oil shell powders can constitute cheap mineral sorbents for environmental cleaning.

\section{References}

1. A. Capodaglio, Resources, vol. 6, $\mathrm{n}^{\circ}$ 2, p. 22, (2017).

2. Jeevanantham, A. Saravanan, R. V. Hemavathy, P. S. Kumar, P. R. Yaashikaa, et D. Yuvaraj, Environ. Technol. Innov., vol. 13, p. 264-276, (2019).

3. A. Bielen et al., Water Res., vol. 126, p. 79-87, (2017).

4. H. Otsuka, in Natural Products Isolation, S. D. Sarker, Z. Latif, et A. I. Gray, Éd. Totowa, NJ: Humana Press, p. 269-27, (2006).

5. G. Mendow, C. I. Grosso, A. Sánchez, et C. A. Querini, Chem. Eng. Res. Des., vol. 125, p. 348-360, (2017).

6. D. J. Miller, D. R. Dreyer, C. W. Bielawski, D. R. Paul, et B. D. Freeman, Angew. Chem. Int. Ed., vol. 56, 
$\mathrm{n}^{\mathrm{o}}$ 17, p. 4662-4711, avr. (2017).

7. S. Saoiabi, K. Achelhi, S. Masse, A. Saoiabi, A. Laghzizil, et T. Coradin, Colloids Surf. Physicochem. Eng. Asp., vol. 419, p. 180-185, (2013).

8. J. Youngran, M. Fan, J. Van Leeuwen, et J. F. Belczyk, J. Environ. Sci., vol. 19, n 8, p. 910-919, (2007).

9. F. T. Ademiluyi et E. O. David-West, ISRN Chem. Eng., vol. 2012, p. 1-5, déc. 2012.

10. S. Mnasri-Ghnimi et N. Frini-Srasra, Appl. Clay Sci., vol. 179, p. 105151, (2019).

11. H. El Boujaady, A. El Rhilassi, M. Bennani-Ziatni, R. El Hamri, A. Taitai, et J. L. Lacout, Desalination, vol. 275, no 1-3, p. 10-16, (2011).

12. M. Hong et al., Chem. Eng. J., vol. 359, p. 363-372, (2019).

13. N. Hegyesi, R. T. Vad, et B. Pukánszky, Appl. Clay Sci., vol. 146, p. 50-55, (2017).

14. A. Aboulkas et K. El Harfi, Oil Shale, vol. 25, n 4, p. 426, (2008).

15. E. Khouya et al., p. 7, (2005).

16. H. Ouasif, S. Yousfi, M. L. Bouamrani, M. E. Kouali, S. Benmokhtar, et M. Talbi, p. 10, (2013).

17. Y. Miyah, A. Lahrichi, M. Idrissi, A. Khalil, et F. Zerrouq, Surf. Interfaces, vol. 11, p. 74-81, (2018).

18. M. Oumam et al., Oil Shale, vol. 37, n 2, p. 139, (2020).

19. A. Gouza et al., Environ. Sci. Pollut. Res., vol. 24, $\mathrm{n}^{\mathrm{o}} 33$, p. 25977-25985, (2017).

20. El. H. Chafyq et al., Chem. Phys. Lett., vol. 778, p. 138707, (2021).

21. El. H. Chafyq et al., Groundw. Sustain. Dev., vol. 12, p. 100532, (2021).

22. E. C. Moine, M. Tangarfa, M. Khachani, A. El Hamidi, M. Halim, et S. Arsalane, Fuel, vol. 180, p. 529-537, (2016).

23. S. Mansouri et al., Mater. Environ. Sci.p. 6, (2017). 